\title{
QUALIDADE DE MILHO VERDE CULTIVADO EM SISTEMAS DE PRODUÇÃO ORGÂNICO E CONVENCIONAL
}

\author{
LUCINÉIA DE PINHO ${ }^{1}$, MARIA CRISTINA DIAS PAES ${ }^{2}$, ANNA CHRISTINA DE \\ ALMEIDA $^{1}$ e CÂNDIDO A. DA COSTA ${ }^{1}$
}

\begin{abstract}
${ }^{1}$ Instituto de Ciências Agrárias - ICA/UFMG, CP. 135, CEP 39.404-006, Montes Claros, MG. lucineiapinho@hotmail.com,aca2006@nca.ufmg.bre candido-costa@nca.ufmg.br ${ }^{2}$ Embrapa Milho e Sorgo, CP. 151, CEP 35701-970, Sete Lagoas, MG. mcdpaes@cnpms.embrapa.br
\end{abstract}

Revista Brasileira de Milho e Sorgo, v.7, n.3, p. 279-290, 2008

RESUMO - Avaliaram-se as características agronômicas e físico-químicas de milho verde cultivado em sistemas de produção orgânico e convencional. Utilizou-se o delineamento experimental inteiramente casualizado, em esquema fatorial 4 x 2 , sendo quatro cultivares (AG 1051, BR 106, SWB 551 e VIVI), nos sistemas orgânico e convencional, com três repetições. As características agronômicas analisadas foram peso das espigas com palhas (PP) e despalhadas (PD), peso dos grãos (PG), peso do sabugo (PS), peso da palha (P), comprimento da espiga com palha (CE), percentual relativo de grãos (PRG), percentual relativo de palha (PRP) e percentual relativo de sabugo (PRS). Foram, ainda, analisados o teor de umidade e as características físico-químicas ( $\mathrm{pH}$, acidez titulável e sólidos solúveis totais) dos grãos verdes. As espigas produzidas no sistema convencional apresentaram PP, PD e PG superiores aos das espigas produzidas em sistema orgânico, para a cultivar AG 1051. O mesmo comportamento foi observado para o CE da cultivar SWB 551 e o PG da cultivar BR 106. No sistema convencional, a cultivar AG 1051 destacou-se nas características agronômicas avaliadas. Os valores médios de $\mathrm{pH}$, diferentemente da acidez, foram superiores no cultivo orgânico. A cultivar SWB 551 apresentou maior percentual de sólidos solúveis entre as cultivares. Portanto, o sistema de produção influencia as principais características de qualidade do milho verde. Palavras-chave: Zea mays, qualidade, análises químicas, aspectos agronômicos. 


\title{
QUALITY OF GREEN CORN GROWN UNDER ORGANIC AND CONVENTIONAL CONDITIONS
}

\begin{abstract}
The present study evaluated the agronomic and physical-chemical characteristics of green corn grown under organic and conventional conditions. A completely randomized design in a 4 x 2 factorial scheme was used, consisting of four corn varieties (AG 1051, BR 106, SWB 551 and VIVI) and two farming systems (organic and conventional), with three replications. The samples of green corn were evaluated for the following agronomic characteristics: weight of the ears with husk (PP) and without husk (PD); grain weight (PG); cob weight (PS); straw weight (P); ear length (EC); percentage of grains (PRG), straw (PRP) and corncob (PRS). Moisture and physicochemical properties ( $\mathrm{pH}$, acidity and soluble solids) in the kernels were also evaluated. Ears of the AG 1051 green corn produced under the conventional system presented higher PP, PD and PG than those in the organic system. The same trend was observed for EC in SWB 551 and PG in BR 106. Under the conventional system, AG 1051 was considered the top cultivar for green corn production. The average levels of $\mathrm{pH}$, unlike acidity, were highest in the organic system. Among cultivars, SWB 551 showed a highest percentage of soluble solids in immature kernel. Thus, the production system plays an important role in the quality attributes of green corn.
\end{abstract} Key words: Zea mays, ear quality, chemical analysis, agronomic aspects

O cultivo de milho destinado à produção de milho verde vem aumentado de forma significativa, em função de sua lucratividade, visto que, na forma de grãos verdes, o valor de comercialização é maior, quando comparado com o milho na forma de grãos secos. Além disso, a sua produção absorve, principalmente, mão-de-obra familiar, que contribui para a geração de empregos em pequenas e médias propriedades, particularmente na época da colheita, que é realizada de forma manual (Cruz et al., 2006). Outro fator que contribui para o crescimento da produção de milho verde é a maior diversificação de uso desse produto pelo mercado, podendo ser comercializado para consumo nas mais diversas formas, desde os grãos in natura, cozidos ou como ingrediente na fabricação de diversos produtos 
da culinária brasileira (Matos et al., 2007). Por esses motivos o milho verde é comercializado em todo o Brasil.

Mundialmente, há um mercado potencial para os produtos orgânicos, incluindo o milho verde, uma vez que existe grande interesse de uma parcela da população em deixar de consumir produtos da agricultura convencional, cuja atividade, reconhecidamente, envolve o emprego de elevadas quantidades de adubos sintéticos e pesticidas, os quais derivam de fontes de energia não renováveis, sendo um modelo de produção não sustentável (Caporal $\&$ Costabeber, 2003). A oferta de espigas de boa qualidade e produzidas em sistema de cultivo orgânico pode favorecer o valor de venda desse produto em até $30 \%$, quando comparado às espigas cultivadas em sistema convencional (Viglio, 1996).

Apesar da tendência comercial favorável ao milho verde orgânico, ainda são escassas as informações sobre o comportamento de cultivares e suas características sob cultivo orgânico (Araújo et al., 2000). Além disso, é reduzido o acervo de estudos que permitem a obtenção de conclusões claras sobre o impacto dos sistemas de produção na qualidade dos alimentos, uma vez que falhas na condução dos experimentos inviabilizam uma comparação válida das características do milho verde em cada sistema de produção. Portanto, o presente trabalho teve por objetivo avaliar as características agronômicas e físico-químicas de cultivares de milho verde, em sistemas de produção orgânico e convencional.

\section{Material e Métodos}

O cultivo do milho foi conduzido na área experimental da Embrapa Milho e Sorgo, em Sete Lagoas/MG, na safra de 2007/2008, conforme recomendações técnicas para os dois sistemas de cultivo estudados. As plantas cultivadas no sistema orgânico ficaram separadas das cultivadas em sistema convencional a uma distância mínima de $500 \mathrm{~m}$, atendendo à recomendação técnica descrita em Brasil (2003), sendo que a área para o cultivo orgânico havia permanecido em pousio por um período de cinco anos. A técnica utilizada para o preparo do solo no sistema de produção orgânico constituiu do uso de grade pesada e grade niveladora e, no sistema convencional, foi feita a dessecação com herbicida Glyphosate 1080 g.ha-1 ${ }^{-1}$ Foi aplicada a técnica de plantio mecanizado, para os dois sistemas. No sistema convencional, foi utilizada a adubação de plantio com 300 $\mathrm{kg} \cdot \mathrm{ha}^{-1}$ da fórmula $8(\mathrm{~N}): 28(\mathrm{P} 2 \mathrm{O} 5): 16(\mathrm{~K} 2 \mathrm{O})$ + Zn e, na adubação de cobertura, 100 kg.ha ${ }^{-1}$ de $\mathrm{N}$, na forma de uréia. $\mathrm{O}$ controle de plantas espontâneas, no sistema orgânico, 
foi realizado por meio de capina manual e, no sistema convencional, com a aplicação de $1000 \mathrm{~g}+32$ g.ha $^{-1}$ (Atrazine + Nicosulfuron). Para o manejo da lagarta-do-cartucho, foram utilizadas três aplicações de Bacolovirus, com 1 L.ha ${ }^{-1}\left(3 \times 10^{10}\right.$ esporos de BT ha $\left.{ }^{-1}\right)$, em ambos os sistemas de produção.

O delineamento laboratorial utilizado no experimento foi o inteiramente casualizado, com três repetições, sendo os tratamentos dispostos em esquema fatorial $4 \times 2$, correspondentes a quatro cultivares (AG 1051, BR 106, SWB 551 e VIVI) e dois sistemas de cultivo (orgânico e convencional). As unidades experimentais foram constituídas de dez espigas de cada cultivar. A amostragem foi realizada após a colheita aleatória de trinta espigas por cultivar, aos 70 dias após o plantio, seguida de seleção das mesmas, respeitando o critério de homogeneidade do estádio de desenvolvimento do grão, leitoso, baseado nas exigências de mercado para milho verde, com relação a espigas destinadas ao consumo humano.

A colheita foi realizada manualmente, nas primeiras horas da manhã, sendo as espigas transferidas com palha ao laboratório, em container refrigerado. Para a verificação das características agronômicas das espigas, as amostras foram pesadas em balança analítica, para obtenção do peso das espigas com palha (PP) (g), e avaliadas quanto ao comprimento da espiga com palha $(\mathrm{CE})(\mathrm{cm})$. Em seguida, todas as espigas de cada tratamento foram despalhadas, lavadas sequencialmente em água corrente e água destilada, sendo, então, secadas em papel toalha e pesadas, para a obtenção do peso de espigas despalhadas (PD) (g). Os grãos foram retirados das espigas mediante corte com facas e pesados, para a obtenção do peso fresco de grãos (PG) (g). Foram, ainda, determinados os pesos do sabugo (PS) (g) e da palha $(\mathrm{P})(\mathrm{g})$.

$\mathrm{O}$ percentual relativo de grãos (PRG), palha (PRP) e sabugo (PRS) foram determinados utilizando as fórmulas:

$$
\begin{gathered}
\mathrm{PRG}=100 \times \mathrm{PG} / \mathrm{PP} \\
\mathrm{PRP}=100 \times \mathrm{P} / \mathrm{PP} \\
\mathrm{PRS}=100 \times \mathrm{PS} / \mathrm{PP}
\end{gathered}
$$

Para a avaliação das propriedades físico-químicas, as amostras dos grãos de milho verde retirados das espigas foram quarteadas, homogeneizadas em liquidificador e, imediatamente, avaliadas quanto ao teor percentual de umidade, determinado pelo método de secagem em estufa, ao $\mathrm{pH}$, determinado em pHmetro digital (Quimis ${ }^{\circledR}$, modelo Q-400HM portátil), à acidez titulável (expressa em \% de ácido cítrico) e ao teor de sólidos solúveis, determinado em refratômetro 
digital (Atago ${ }^{\circledR}$, modelo N-1E), seguindo métodos recomendados pela AOAC (2000). As análises foram conduzidas no Laboratório de Qualidade de Grãos da Embrapa Milho e Sorgo. Todas as análises foram realizadas em triplicata. Os dados obtidos foram submetidos à análise de variância, sendo as médias comparadas pelo teste de Tukey, quando detectada significância para a ANOVA a $\mathrm{p}=0,05$.

\section{Resultados e Discussão}

Aanálise das características agronômicas permite selecionar cultivares de milho para serem utilizadas no sistema orgânico de produção, uma vez que, nesse sistema, são exigidas certas características, tais como, capacidade produtiva, adaptabilidade $\mathrm{e}$ rusticidade, devido à necessidade de redução de uso de insumos sintéticos, aumentando a necessidade de resgatar e utilizar cultivares menos dependentes de insumos, por serem mais adaptadas às condições locais (Machado, 1998). As características peso da espiga com palha (PP), peso da espiga despalhada (PD) (Tabela 1), comprimento da espiga com palha (CE) e peso dos grãos de milho verde (PG) (Tabela 2) foram influenciadas pela interação dos fatores sistema de produção e cultivares.

As espigas de milho verde da cultivar AG 1051 apresentaram médias de PP, PD (Tabela 1) e PG (Tabela 2) significantemente superiores no sistema convencional, quando comparado ao cultivo no sistema orgânico. O mesmo comportamento foi observado para a média de $\mathrm{CE}$ das espigas da cultivar SWB 551 e a média de PG da cultivar BR 106. Entretanto, houve tendência das demais cultivares de apresentar PP, PD, CE e PG

TABELA 1. Peso da espiga com palha (PP) e peso da espiga despalhada (PD) das cultivares de milho verde, cultivadas em sistemas de produção orgânico e convencional.

\begin{tabular}{ccccc}
\hline & \multicolumn{2}{c}{ PP $(\mathbf{g})^{\mathbf{1}}$} & \multicolumn{2}{c}{ PD (g) } \\
\hline Cultivares & Convencional & Orgânico & Convencional & Orgânico \\
\hline AG 1051 & $420,15 \pm 50,11 \mathrm{Aa}$ & $300,05 \pm 40,74 \mathrm{Ab}$ & $275,05 \pm 31,05 \mathrm{Aa}$ & $171,13 \pm 21,07 \mathrm{Ab}$ \\
BR 106 & $307,34 \pm 33,84 \mathrm{Ba}$ & $287,65 \pm 65,81 \mathrm{Aa}$ & $187,82 \pm 31,43 \mathrm{Ba}$ & $169,69 \pm 28,20 \mathrm{Aa}$ \\
SWB 551 & $316,48 \pm 34,15 \mathrm{Ba}$ & $280,42 \pm 24,56 \mathrm{Aa}$ & $207,68 \pm 23,59 \mathrm{Ba}$ & $192,83 \pm 23,90 \mathrm{Aa}$ \\
VIVI & $308,26 \pm 26,76 \mathrm{Ba}$ & $297,67 \pm 48,40 \mathrm{Aa}$ & $195,85 \pm 18,85 \mathrm{Ba}$ & $179,78 \pm 19,74 \mathrm{Aa}$ \\
\hline C.V. (\%) & \multicolumn{2}{c}{13,51} & \multicolumn{2}{c}{12,88}
\end{tabular}

${ }^{1}$ Médias seguidas da mesma letra maiúscula, comparando as cultivares e minúscula, comparando os sistemas, não diferem estatisticamente entre si, a 5\% de probabilidade, pelo teste Tukey. 
TABELA 2. Comprimento das espigas com palha (CE) e peso dos grãos (PG) das cultivares de milho verde, cultivadas em sistemas de produção orgânico e convencional.

\begin{tabular}{ccccc}
\hline & \multicolumn{2}{c}{ CE (cm) } & \multicolumn{2}{c}{ PG(g) } \\
\hline Cultivares & Convencional & Orgânico & Convencional & Orgânico \\
\hline AG 1051 & $31,83 \pm 2,04 \mathrm{Aa}$ & $30,05 \pm 1,80 \mathrm{Aa}$ & $152,78 \pm 23,45 \mathrm{Aa}$ & $82,11 \pm 18,01 \mathrm{Bb}$ \\
BR 106 & $27,23 \pm 2,63 \mathrm{Ba}$ & $27,82 \pm 3,22 \mathrm{ABa}$ & $106,16 \pm 27,82 \mathrm{Ba}$ & $82,62 \pm 16,97 \mathrm{Bb}$ \\
SWB 551 & $27,82 \pm 2,33 \mathrm{Ba}$ & $24,45 \pm 1,44 \mathrm{Cb}$ & $116,09 \pm 19,74 \mathrm{Ba}$ & $116,16 \pm 27,27 \mathrm{Aa}$ \\
VIVI & $26,82 \pm 1,18 \mathrm{Ba}$ & $26,20 \pm 2,79 \mathrm{BCa}$ & $93,77 \pm 25,30 \mathrm{Ba}$ & $80,14 \pm 17,17 \mathrm{Ba}$ \\
\hline C.V. $(\%)$ & \multicolumn{2}{c}{8,19} & \multicolumn{2}{c}{21,57}
\end{tabular}

${ }^{1}$ Médias seguidas da mesma letra maiúscula, comparando as cultivares e minúscula, comparando os sistemas, não diferem estatisticamente entre si, a $5 \%$ de probabilidade, pelo teste Tukey.

semelhantes nos dois sistemas de cultivo. De acordo com Santos et al. (2005), a produção no sistema orgânico é menor que a esperada em sistema convencional, no primeiro ano de cultivo. A conversão de áreas do sistema de produção convencional para o orgânico requer intervalos de dois a três anos, para permitir que o solo e o ambiente atinjam o equilíbrio (Theodoro, 2001). Portanto, possivelmente, a diferença de produção entre sistemas de cultivo não foi observada nesse experimento, para todas as cultivares, devido ao mesmo ter sido implantado em área onde já havia acontecido o processo de conversão.

No sistema convencional, a cultivar AG 1051 apresentou médias superiores de PP (420,2 g), PD (275,1 g), CE (31,83 cm) e PG (152,78 g), quando comparada às demais cultivares, sendo considerado o material com os melhores valores para essas características, neste sistema de produção (Tabela 1 e 2). Além disso, as médias de PP, PD e PG foram significativamente reduzidas quando essa cultivar foi produzida sob condições orgânicas. No milho verde, o grão é a parte consumida diretamente e utilizada na elaboração de pratos tradicionais na culinária, sendo que o consumidor dá preferência a espigas de maior comprimento e, por esse motivo, esses atributos são considerados na comercialização do milho para consumo in natura ou para a indústria de enlatados (Albuquerque et al., 2008). A cultivar AG 1051 não apresentou diferença significativa especificamente para essa característica, entre os sistemas de produção, e, portanto, a cultivar AG 1051 poderia ser indicada para o sistema orgânico, com base nessa característica. 
A cultivar SWB 551 apresentou destaque para a característica peso de grãos, no sistema orgânico. Não houve diferença significativa entre as cultivares, para as características PP e PD, no sistema orgânico (Tabela 1). As cultivares produziram espigas com médias semelhantes quanto a peso com e sem palha, no sistema orgânico. Os milhos doces SWB 551 e VIVI apresentaram o menor $\mathrm{CE}$, quando comparados às demais cultivares, nesse sistema (Tabela 2). O plantio da cultivar SWB 551, em cultivo orgânico, levou à redução do comprimento de espigas dessa cultivar, o que influenciou sensivelmente nos valores de $\mathrm{CE}$; caso contrário, a tendência, para essa característica, seria semelhante para as cultivares produzidos em sistema orgânico e em cultivo convencional. Segundo Oliveira et al. (1987), uma das características quantitativas comerciais avaliadas para milho verde é o comprimento de espiga com palha, quando o milho se destina às feiras livres $\mathrm{e}$ quitandas. No entanto, o material SWB 551, embora com menor comprimento de espiga, apresentou maior rendimento de grãos verdes, no sistema de produção orgânico, comparado às demais cultivares.

As médias de peso do sabugo (PS), peso da palha $(\mathrm{P})$, percentual relativo de grãos $(\mathrm{PRG})$, percentual relativo de palha (PRP) e o percentual relativo de sabugo (PRS) (Tabela 3) diferiram apenas entre cultivares, não havendo efeito do sistema de cultivo e da interação de ambos os fatores nesses parâmetros.

Dentre as cultivares, o híbrido experimental doce VIVI apresentou valor médio de PS (100,9 g) superior às médias das cultivares BR 106 (84,4 g) e SWB 551 (60g ) e não diferiu do AG 1051 (Tabela 3). Na produção de derivados do milho verde, como é o caso da pamonha, uma das características exigidas pelo mercado são cultivares que apresentem melhor rendimento de palha (Pereira Filho \& Cruz, 2002). A cultivar AG 1051 apresentou valor médio de peso da palha (P) $(146,0 \mathrm{~g})$ superior, quando comparada às cultivares SWB $551(98,2 \mathrm{~g})$ e VIVI $(115,2 \mathrm{~g})$, mas semelhante à média das espigas do BR 106. Os valores médios de PRG das cultivares AG $1051(31,95 \pm 6,6 \%)$ e VIVI $(29,0 \pm 7,6 \%)$ foram inferiores aos da cultivar SWB 551 $(39,0 \pm 6,9 \mathrm{~g})$.

Os milhos dentados (AG 1051 e BR 106) apresentaram valor médio de PRP superiores ao do milho doce SWB 551 (Tabela 3), o que seria uma característica adequada para utilização pelas pamonharias, que necessitam de palha para confecção de pamonhas. Além disso, de acordo com Albuquerque (2005), as cultivares ideais para produção de milho verde devem apresentar bom empalhamento, caracterizado pela integridade e rendimento 
TABELA 3. Peso do sabugo (PS), peso da palha (P), percentual relativo de grãos (PRG), percentual relativo de palha (PRP) e percentual relativo de sabugo (PRS) das cultivares de milho verde, cultivadas em sistemas de produção orgânico e convencional.

\begin{tabular}{cccccc}
\hline Cultivares & PS (g) $)^{\mathbf{1}}$ & P (g) & PRG & PRP & PRS \\
\hline AG 1051 & $96,65 \pm 15,30 \mathrm{AB}$ & $146,01 \pm 39,80 \mathrm{~A}$ & $31,95 \pm 6,61 \mathrm{~B}$ & $40,44 \pm 7,43 \mathrm{~A}$ & $27,60 \pm 5,60 \mathrm{~B}$ \\
BR 106 & $84,37 \pm 28,26 \mathrm{~B}$ & $118,74 \pm 35,43 \mathrm{AB}$ & $32,63 \pm 10,13 \mathrm{AB}$ & $39,33 \pm 7,40 \mathrm{~A}$ & $28,04 \pm 7,83 \mathrm{~B}$ \\
SWB 551 & $84,13 \pm 16,15 \mathrm{~B}$ & $98,20 \pm 25,56 \mathrm{~B}$ & $38,95 \pm 6,90 \mathrm{~A}$ & $32,65 \pm 6,48 \mathrm{~B}$ & $28,39 \pm 5,71 \mathrm{AB}$ \\
VIVI & $100,86 \pm 16,97 \mathrm{~A}$ & $115,15 \pm 32,69 \mathrm{~B}$ & $29,00 \pm 7,64 \mathrm{~B}$ & $37,51 \pm 6,91 \mathrm{AB}$ & $33,49 \pm 5,38 \mathrm{~A}$ \\
\hline C.V. (\%) & 21,40 & 27,61 & 22,95 & 18,99 & 20,92
\end{tabular}

'Médias seguidas da mesma letra maiúscula, comparando as cultivares, não diferem estatisticamente entre si, a 5\% de probabilidade, pelo teste Tukey.

da palha, o que favorece a manutenção da umidade dos grãos e a melhor conservação das espigas. A cultivar VIVI, para a característica PRP, apresentou semelhança ao milho doce SWB 551 e aos milhos dentados. A cultivar VIVI apresentou valor médio de PRS $(33,5 \%)$ semelhante aquele da cultivar SWB 551 $(28,4 \%)$ e superior em relação às cultivares AG 1051 (27,6\%) e BR 106 (28,1\%).

Os teores de umidade nos grãos de milho verde não foram influenciados por nenhum dos fatores estudados (ANOVA, $\mathrm{p}>0.05$ ). $\mathrm{O}$ teor de umidade observado para as cultivares foi, em média, 79,7 $\pm 4,6$, correspondendo ao estádio de maturação adequado dessa hortaliça, conforme descrito por Sawazaki et al. (1979).

Os valores médios de $\mathrm{pH}$ e acidez total titulável nos grãos de milho verde diferiram apenas entre os sistemas de cultivo $(p<0.05)$ (Figura 1). Os grãos do milho verde produzidos em sistema orgânico apresentaram valor médio de $\mathrm{pH}(7,1)$ superiores àqueles da hortaliça produzida em sistema convencional $(6,8)$, com resultado inverso para a acidez total titulável. Esses dados foram relativamente próximos àqueles relatados na literatura para milho verde, classificado como um alimento pouco ácido e, por isso, favorável à multiplicação de microrganismos (Leme, 2007). O milho verde colhido é considerado um alimento altamente perecível, pelo seu alto teor de água, o que torna seu período de comercialização bastante restrito (Silva et al., 1997). Os maiores valores de $\mathrm{pH}$ e menores valores de acidez obtidos para o milho verde produzido em sistema orgânico sugerem maior susceptibilidade desse produto a possíveis microrganismos deterioradores e patogênicos 

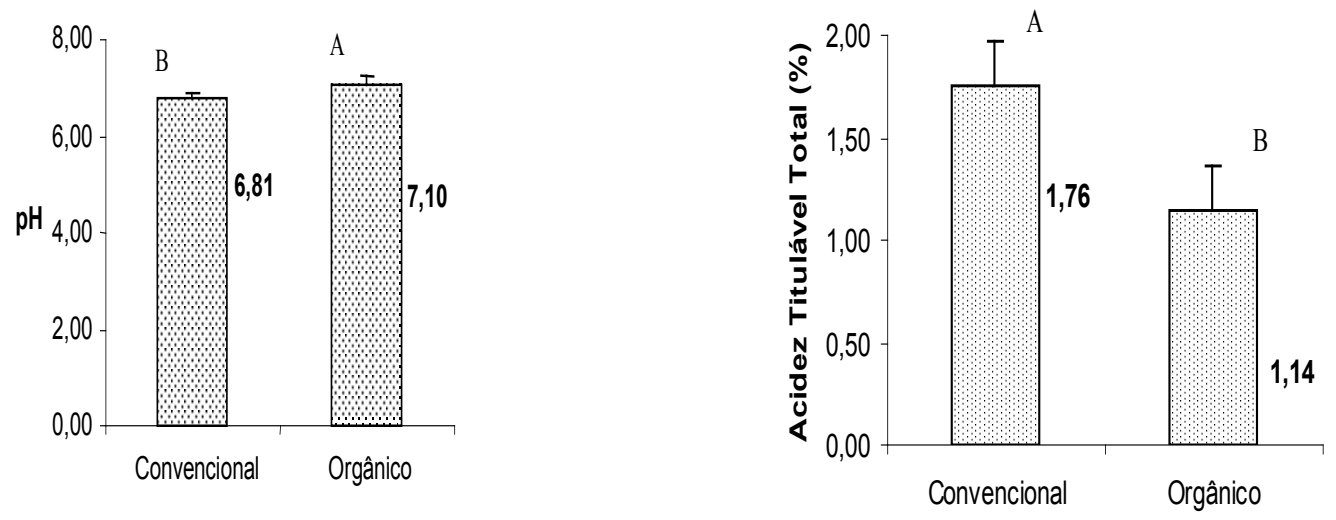

FIGURA 1. Teor médio de $\mathrm{pH}$ e acidez das cultivares de milho verde, cultivadas em sistemas de produção orgânico e convencional. Médias seguidas da mesma letra maiúscula, comparando os sistemas de cultivo, não diferem estatisticamente entre si, a 5\% de probabilidade, pelo teste Tukey. Resultados são expressos em base fresca.

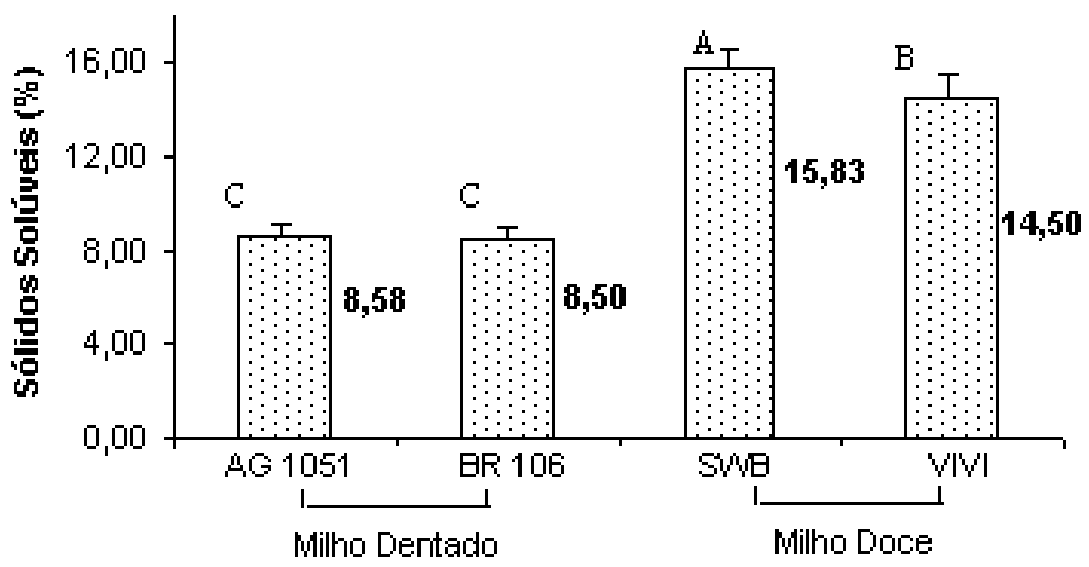

FIGURA 2. Teor médio de sólidos solúveis das cultivares de milho verde, cultivadas em sistemas de produção orgânico e convencional. Médias seguidas da mesma letra maiúscula, comparando as cultivares, não diferem estatisticamente entre si, a 5\% de probabilidade, pelo teste Tukey. Resultados são expressos em base fresca. 
e, consequentemente, potencializam a característica de perecibilidade, quando comparado ao milho verde produzido em sistema convencional.

O teor médio de sólidos solúveis nos grãos verdes de milho foi influenciado apenas pelo fator cultivar $(p<0,05)$, sendo que os milhos doces SWB $551(15,83)$ e VIVI $(14,50)$ apresentaram percentual de sólidos solúveis significativamente superior ao das demais cultivares (Figura 2). Isso pode ser explicado pelo fato de os milhos doces possuírem distinta composição de açúcares nos grãos, o que lhes confere maior teor de sólidos solúveis (Matos et al., 2007).

\section{Conclusões}

De modo geral, pode-se obter, através do sistema orgânico, milho verde com qualidade de espigas para comercialização, quando comparado ao sistema convencional.

A produção de milho no sistema orgânico resulta em teores médios mais altos de $\mathrm{pH}$ e menor acidez titulável em grãos verdes.

\section{Literatura Citada}

\section{ALBUQUERQUE， C.J.B. Desempenho} de híbridos de milho verde na região sul de Minas Gerais. 2005. 56p. Dissertação
(Mestrado em Fitotecnia) - Universidade Federal de Lavras, Lavras.

ALBUQUERQUE, C.J.B., VON PINHO, R.G.; SILVA, R. Produtividade de híbridos de milho verde experimentais e comerciais. Journal of Biosciense, Uberlândia, PG, v. 24, n. 2, p. 69-76, 2008.

ARAÚJO, P.C. de; PERIN, A.; MACHADO, A.T. de; ALMEIDA, D.L. de. Avaliação de diferentes variedades e milho para o estádio de "verde" em sistemas orgânicos de produção. In: CONGRESSO NACIONAL DE MILHO E SORGO, 23, Uberlândia, 2000. A inovação tecnológica no contexto dos mercados globalizados: [resumos expandidos]. Sete Lagoas: ABMS/Embrapa Milho e Sorgo/ Universidade Federal de Uberlândia, 2000. CD ROM.

ASSOCIATION OF OFFICIAL ANALYTICAL CHEMISTS - AOAC. Official methods of analysis of the AOAC international. 17 th. ed. Washington, DC: AOAC, 2000. 1.115p.

BRASIL. Lei Federal n. 10.831. Dezembro, 2003. Dispõe sobre normas para a produção de produtos orgânicos vegetais e animais. Diário Oficial da República Federativa do Brasil, Brasília, DF, 23 dez. 2003, Seção 1, p. 11.

CAPORAL. F.R.; COSTABEBER, J.A. Segurança alimentar e agricultura suntentável: uma perspectiva agroecológica. 
Porto Alegre: EMATER/ RS - ASCAR, 14p. (EMATER/RS - ASCAR, Ciência e Ambiente, 27), 2003.

CRUZ, J. C.; KONZEN, E.A.; FILHO, I. A. P.; MARRIEL, I.E.; CRUZ, E.; DUARTE, J.O.; OLIVEIRA, M.F.; ALVARENGA, R.C. Produção de milho orgânico na agricultura Familiar. Sete Lagoas: Embrapa-CNPMS, 17p. (Embrapa-CNPMS, Comunicado Técnico, 81), 2006.

EMPRESA BRASILEIRA DE PESQUISA AGROPECUÁRIA - EMBRAPA. Quais os principais cuidados recomendados para colheita de milho verde em espigas? Sete Lagoas: EMBRAPA, 2007. Disponível em: $<$ http://www.cnpms.embrapa.br $>$. Acesso em: 10 jun. 2007.

LEME, A.C. Avaliação e armazenamento de híbridos de milho verde visando a produção de pamonha. 2007. 124p. Dissertação (Mestrado em Ciência e Tecnologia de Alimentos) - Universidade de São Paulo/ Escola Superior de Agricultura "Luiz de Queiroz", Piracicaba/SP.

MACHADO, A.T. Melhoramento genético nas comunidades agrícolas - desenvolvimento de novas variedades e melhoramento integrado In: Milho crioulo: conservação e uso da biodiversidade. AS-PTA, Rio de Janeiro, 1998, p.185.
MATOS, M.J.L.F.; TAVARES, S.A.; SANTOS, F.F.; MELO, M.F.; LANA, M.M. Milho verde. Brasília: EMBRAPA Hortaliças, 2007. Disponível em: <http://www.cnph.embrapa. br/laborato/pos_colheita/dicas/milho_verde. htm>. Acesso em: 03 jun. 2007.

OLIVEIRA, L. A.A.; GROSZMAN A.; COSTA, R. A. Caracteres da espiga de cultivares de milho no estádio verde. Pesquisa Agropecuária Brasileira, Brasília, DF, v. 22, n. 6, p. $587-5921987$.

PEREIRA FILHO, I. A.; CRUZ, J. C. Cultivares de milho para o consumo verde. Sete Lagoas: Embrapa CNPMS. Circular técnica n. 15, 2002. Disponível em: <http:// www.cnpms.embrapa.br $>$. Acesso em 07 de julho de 2008.

SANTOS, I.C., MIRANDA, G.V.; MELO, A.V.; MATOS, R.N.; OLIVEIRA, L.R.; LIMA, J.S.; GALVÃO, J.C.C. Comportamento de cultivares de milho produzidos organicamente e correlações entre características das espigas colhidas no estádio verde. Revista Brasileira de Milho e Sorgo, Sete Lagoas, PG, v.4, n. 1, p. 45-53, 2005.

SAWAZAKI, E.; POMMER, C. V.; ISHIMURA, I. Avaliação de cultivares de milho para utilização no estádio de verde. Ciência e Cultura, v. 31, n. 11, p. 1297, nov. 1979. 
SILVA, P.S.L.; BARRETO, H.E.P.; SANTOS, e convencional. 2001. 214p. Dissertação M.X. A. Avaliação de cultivares de milho (Mestrado) - Universidade Federal de Lavras, quanto ao rendimento de grãos verdes e secos. Lavras.

Pesquisa Agropecuária Brasileira, Brasília, DF, v. 32, n. 1, p. 63-69, 1997.

VIGLIO, E.C.B.L. Produtos orgânicos: uma

THEODORO, V.C.A. Caracterização de tendência para o futuro? Agroanalysis, São produção do café orgânico, em conversão Paulo, SP, v.6, n.12, p. 8-11, 1996. 